\title{
The Impact of Government Policy on Physically Challenged Children in Lagos State, Nigeria
}

\author{
T. O. Ogunleye*, F. A. Fabinu, O. Eruobodo, S. O. Popoola \\ School of Early Childhood Care and Primary Education \\ Michael Otedola College of Primary Education, Noforija, Epe, Lagos State \\ ${ }^{*}$ Corresponding author's email: lastingogunleye [AT] yahoo.com
}

\begin{abstract}
Children with disability are facing problems of integration into the regular classroom setting in Lagos State which eventually deprived them reach their full potentials. This study looked at the impact of government policy on physically challenged children in Lagos State. The paper explained the concept of physically challenged children' historical background of physically challenged children in Nigeria and the need for the implementation of policy concerning physically challenged children were discussed. Consequently, recommendations and conclusion were made. The paper concluded that adequate programme should be embarked on by government to educate people on the need to accommodate physically challenged children in classrooms and the society at large.
\end{abstract}

Keywords---- Government policy, physically challenged children, teachers.

\section{INTRODUCTION}

As in many countries in the world, children with disability in Nigeria are prevented from reaching their full potentials. They meet obstacles in their entry to school, having inadequate care, abandoned and sometimes killed in the society. These in turn contribute to their low-income level and literacy that highlights their poverty plight. In addition, it contributes to their low $\mathrm{p}$ articipation in the society, hidden from others and high reliance on begging in streets.

The World Health Organisation (WHO, 1980) refers to their condition as handicap and as such defines it as :

"The loss or limitation of opportunities to take part in the life of the person with a disability and shortcoming in the environment and in many organized activities in the society, for example, which prevent persons with disabilities from participating, on equal terms. It is a disadvantage for a given individual resulting from impairment or a disability that limits the fulfillment of a role that is normal (depending on sex, social and cultural factors for that individual) (WHO, 1980, pp.29)

In the same vein, Oladejo (2011) opined that these physically challenged children are children with one form of disabilities or the other, capable of limiting their involvement and participation on the regular educational programmes and subsequently affect their academic performance and functionality in the society. Kirk, Gallagher and Amastasiow (1997) in Obani (2006) defined physically challenged as a condition that interferes with the individual's (child) ability to use his body.

In reality, bridging the gap between policy developers and translating the policy into reality has created a major concern of stakeholders particularly in education sector. Today Nigerian government has realized that good health, equal access to education, protective from violence irrespective of gender, is the right of every child irrespective of race, colour, religion or nature of disabilities. Hence, adequate intervention need to be done in favour of physically challenged children. Therefore, this shall lead to enrolment of such children into normal classroom setting which is referred to as "inclusive education".

\section{CONCEPT OF PHYSICALLY CHALLENGED CHILDREN}

The term physically challenged children cannot be pinned down to one definition because not all cultures share the same concepts of disability. In other words, an individual considered having a disability in one culture may not be in another culture (Utley and Obiakor (2004) and Smith (2007) opined that American culture believed in a direct scientific cause and - effect relationship between a biological problem and the developing baby. The American with Disabilities Act (ADA) viewed a child to be physically handicapped if he has an impairment that substantially limits one or more of life's daily activities as well as those who have a history of such conditions without currently displaying symptoms. According 
to World Health Organization (WHO, 1980) in Kotso (2010), physically challenged children are defined as those whose non - sensory physical limitation or health problems interfere with the school attendance or learning to the extent that special service, training, equipments, materials or facilities are required to facilitate learning.

This implies that physically challenged children are not far from the normal school setting but need special attention in the regular classrooms. It should be noted that the programme designed for physically challenged children is not a need which a person (child) has through his or her life span if the remedy commences earlier.

Dictionary of Contemporary English ( $5^{\text {th }}$ Edition) defines physically challenged as somebody with a condition that makes it difficult to perform some or all the basic tasks of daily life. The Child's Rights Act (CRA) 2003 law defines a child as a person who has not yet attained the age of eighteen years. Therefore, the physically challenged children are those under ages eighteen (18) that need to be nurtured and assisted to overcome physical, emotional and mentally challenges so as to develop into responsible adults in a society.

Obani in Ajobiewe (2000) collated and synthesized the belief of Nigeria cultures regarding the cause of physical disability as:

i. $\quad$ A curse on the family or the wider community for offences committed against god or gods;

ii. Anger of the ancestors for breached promises;

iii. A punishment on the child for offences committed;

iv. Parent misconduct especially mother;

There are many reason for the disabilities amongst children. Many factors or situations before or after birth can lead to the abnormalities and disabilities in the children. Sanhu et al (2001) in Kotso (2010) mentioned the characteristics of the physically challenged children to include: mobility, vision, hearing and speech and language. Kirk and Gallager (1989) supported this view that physically challenged children can be described as the severity of physical involvement on mobility and motor skills.

\section{HISTORICAL BACKGROUND OF PHYSICALLY CHALLENGED IN NIGERIA}

In Nigeria today, many children with various health deficiencies such as: diseases, illness, heredity problems, accidents plague, enroll either in the public or private schools but could not participate well in the classrooms setting like their normal peers. However all children are born equally, have rights to education, equal opportunities and participation in society, the physically challenged children find it difficult to adjust to the demands of the society in which they live because of their physical, mental and social limitations. Kotso (2010)

Historically, education of the physically challenged children in Nigeria began during the middle of $20^{\text {th }}$ century, through the efforts of missionaries, non-governmental organization (Cheshire Homes, Ibadan School for the Deaf, Oji River Rehabilitation, Centre for the Blind in Anambra State as well as Pacelli school for the Blind among others) and governmental agencies towards the establishment of various institutions to take care of the needs of the physciall challenged people (Oladejo, 2011; Kotso, 2010; Olagunju, 2007; Mba, 1995).

The Federal Government of Nigeria also recognized the importance of educating the physically challenged children; therefore these sets are not being left unattended to. The Federal Government of Nigeria in the National Policy on Education $(1981,1998)$ spelt it out that "physically challenged children should not be neglected in the education system". In realization of this plan, the Federal Government directed that two percent of positions in establishment should be allocated to qualified disabled persons. It stressed further that state governments should set up vocational centres for the disabled. A look at this to a layman shows that governments are more committed to special education, but very little has been achieved in the implementation. The special schools established were unfair and the services available cannot lead to a satisfactory programme due to poor stakeholders input. Kotso (2001) research work on information resources and services available for the physically challenged children were inadequate for any significant impact in teaching and learning.

In addition, Obiakor (1998) cited in Kotso (2010) reported that the Federal Ministry of Education established a committee to conduct special education activities in collaboration with the Ministries of Health, Social Welfare and Labour. Also, teachers were trained as special educators in the field, but still, there is an alarming rate that the skills, competence and knowledge are not acquired. Sadly enough, millions of naira invested in education sector have not yielded the desired outcomes how much more the special education unit.

The bill on Disability Policy Framework (the Nigerian bill) was proposed for legislation in the year 2000 but did not succeed for one reason or the other. Silverstern (2000) advised that the Disability Policy Framework for Nigeria bill should include it in a guide work with and focus on integration programme at each level. In 2001, the Disability 
Discrimination Act was enacted with the focus on segregation. No wonder, Orukotan (2004) in Fareo (2012) stated that education of the special needs (physically challenged children) started with segregation, but however this segregation failed and the nomenclature had to be changed to mainstreaming or integration which is also known as inclusive education in normal schooling.

The Federal Government of Nigeria in the National Policy on Education (2014, revised) adopted mainstreaming as a replacement of segregation. The policy stated "equal education opportunities for all children, irrespective of their physical, sensory, mental, psychological or emotional disabilities in order to fully contribute their own quota to the development of the nation". This implies that physically challenged children will learn or be educated in the same classroom setting with their counterparts irrespective of their disabilities. The purpose and objectives orf special education programmes as stated in the National Policy on Education, section 7, are as follows:

a. Provide access to education for all person, in an inclusive setting;

b. equalizing educational opportunities for all persons, irrespective of their physical, sensory, mental, psychological or emotional disabilities;

c. provide adequate education for all persons with special needs in order that they may fully contribute their own quota to the development of the nation;

d. provide opportunities for exceptionally gifted and talented persons to develop their talents, natural endowments/ traits at their own pace in the interest of national development; and

e. design a diversified and appropriate curriculum for all the beneficiaries.

Furthermore, the Federal Government established a College of Education called Government Advanced Teacher Training (Special) Education, Oyo, Oyo State in 1977 (now known as, Federal College of Education Special) to produce teachers or specialist for the physically handicapped as well as and gifted children. A special unit was also created at the Federal Ministry of Education while special education section was also created at State Ministries of Education. Some universities also run programmes in their Faculties of Education, namely the University of Ibadan, Calabar, and Jos at both undergraduate and the post-undergraduate levels.

In Nigeria, the condition of the physically challenged children attracts little or no attention. Although the statistical data of physically challenged children is not readily available, the National Population Commission (NPC) placed the number of persons with physical disability at 19 million in Nigeria, children inclusive (Lang and Upah, 2008, Folabi \& Akanbi, 2009 and Adamu, 2009. Furthermore, the World Bank has estimated that persons with disabilities account for up to one in five of the world's poorest people that is those who live on less than one dollar a day and who lack access to good amenities of which Nigeria is among (Elwan, 1999). These figure was estimated from a recent report from inclusion International which documented the poverty and exclusion experienced daily by people (Inclusion International, 2006).

The right of all disabled people including physically challenged children has been reiterated and given a new impetus with the convention on the Right of Persons with Disabilities (CRPD) which was signed on $30^{\text {th }}$ March, 2007 by the representatives of an unprecedented 81 countries. This follows an unequivocal statement made by heads of state and government, adopted by the United Nations General Assembly on May 2002 special session on children.

"Each girl and boy is free and equal in dignity and right; therefore, all forms of discrimination affecting children must end ... we will take all measures to ensure the full and equal enjoyment of all human rights and fundamental freedoms, including equal access to health, education and recreational services, for children with disabilities and children with special needs to ensure the recognition of their dignity, to promote their self-reliance and to facilitate their active participation in the community" (United Nation General Assembly, A word fit for children (2002)

The idea of the inclusion of physically challenged children in the education programme has been advocated by many policy documents like: Convention on the Rights of the Child in 1989, the Jomiten World declaration on Education For All (EFA) 1990, Action Concerning Disabled Persons in 1992, the United Nations Standard Rules on the Equalization of Opportunities, 1993, the Salamanca report and Framework for Action Education of Children with Special Needs, 1994 African Charter on the Rights and Welfare of the Child (ACRWC) in 1999 (Article 13 stated that "every child who is physically challenged shall have the right to special measures of protection and self-reliance participation in the community"), the Dakar Framework for action on education for All, UNESCO 2012. All these acts are targeted towards education for all children irrespective of disability or challenges.

The constitution of Nigeria stated that a citizen of Nigeria irrespective of ethnic groups or disability not deprived by reason of the circumstances of his right. Despite the provisions of the Nigeria constitutions and international treaties signed, physically challenged children in Nigeria are not often taken into consideration with respect to highways, public highways, public buildings and most of them do not have access to special education. This explains why most of them often end up as beggars, uneducated,educational, victims of rape and rituals at childhood. 
Furthermore, high level of illiteracy affects the destitute structure and specialized institutions to cater for the needs of these sets of children. And this as well affects the parent's mentality that felt that physically challenged children cannot contribute any quota to the society or to the national development and growth.

The 2012, Day of the African child, with the theme "The Rights of Children with Disabilities: the duty to protect, respect, promote and fulfill" was an opportunity to examine the plight of the physically challenged children in the country with the intention of using laws and social engineering to protect, respect and promote their well being as normal members of the society. The provision is being spelt out in CRC (Convention on the Rights of the Child) in article: 2, 9, 18, 19 etc backed up African Child Day Celebrated that year.

Significant process is being made in combating major causes of physically handicapped conditions in Nigeria through the UNICEF programmes, Example are: Provision of safe water through construction of bore holes and giving iodine and vitamin A to children at the designated areas. Different Acts or programmes advocating for the children have changed the recorded number of children who are physically challenged in Nigeria to a minimum level. However an urgent need must be raised on awareness about these set rights, capabilities and removing the obstacles faced by the physically challenged children in becoming active members in the various communities in which they live and learn.

In Lagos State, provisions for the well being of the physically challenged children have been felt through construction of homes and clinics. Although eradication is still the order of the day because these set of children are segregated from others and there is no focus on inclusive education Anyaele (2012) declares that "the budgetary allocation at the Federal Ministry of Women Affairs for physically challenged children drops every year. Even the 2012 budget allocation does not make provision for persons with disabilities". This shows that little quota is being given to education of the physically challenged children.

The Millennium Development Goals (MDG's) form a blueprint agreed by all the world's countries and leading development institutions for the year 2015 as a crucial inclusive framework for advancing the human rights and the quality of life of persons with disability and their families. Despite the omission of specific reference to persons with disabilities in the 18 targets for 2015 or the 48 monitoring indicators of the MDG framework, recognition has nonetheless been given to their needs. An international effort is now underway for the explicit inclusion of a disability dimension into the fiveyear review of MDG achievements. However, concerns remain over the ability to translate the international goals into reality, as expressed, for example by a disability and development worker in India (UNICEF, 2009).

\section{FACTORS AFFECTING THE DEVELOPMENT OF PROGRAMME FOR CHILDREN WITH PHYSICAL DISABILITIES IN LAGOS STATE}

Development of programme for children with disabilities in Lagos state is geared towards learning with ease in the regular classroom. Unfortunately, the implementation of policy on disabilities in developing countries such as Nigeria, has some constraints which include: lack of qualified teachers, lack of learning facilities, attitudes of able pupils towards physically challenged children, attitude of physically challenged children in the regular classrooms, lack of motivation for teachers and poor monitoring of special education programme have greatest impact on the development of programmes for physically challenged children in Lagos state.

i. $\quad$ Lack of Qualified Teachers: Most teachers are ill-equipped to attend to the educational needs of pupils with physical challenges in the regular classroom. Sometimes, regular classroom teachers are frightened by the mere presence of a pupil using crutches. The teacher tends to be disturbed by the frequent questions raised by pupils with special needs. Some teachers even get angry and send children with disabilities (physically challenged) out of the class for asking too many questions. Some teachers are even scared of how to teach them. In the view of Uyanwa and Akanbi (2002), and Kanu, Lazarus and Ikujini (2005) research works showed that unqualified teachers hinder the development of programmes for physically challenged children. In the view of Uyanwa and Akanbi (2002), there is still a dearth of special education teachers in the country (Nigeria - Lagos state) and because non-specialist teachers are still being employed to work with children with special needs in Lagos state.

ii. Lack of Learning Facilities: Financing special education is inevitable in the education of the special needs children. Children with special needs require teaching and learning facilities which are modified to suit their handicapped conditions. Unfortunately, most of the schools lack such facilities, for example: braille reading materials, measurement kits for the visually impaired, hearing aids for hearing impaired, toys, wall charts and flash cards for the intellectually retarded, special toys, cut-out tables and movable chalk boards and pencil for the physically handicapped and health impaired, films for models, slide, pictures, toys for the emotionally disturbed, to mention a few.

iii. $\quad$ Attitudes of Non-Disabled Pupils Towards Special Needs Pupils: the attitude of non-disabled pupils towards physically handicapped children is a hindrances to the development of programmes for these sets of 
children. In most cases, the non-disabled pupils are not happy to find such pupils in their class. It is not uncommon to find non-disabled pupils not sitting beside physically challenged children (such as the epileptic, albino, physically impaired). The non-disabled pupils' behaviour towards the physically challenged children portray negative attitude towards them and thereby some of them withdraw from schools.

iv. Attitudes of Physically Challenged Children in the Regular Classroom: Some children with physical disabilities constitute nuisance to themselves; teachers and peers in the regular classroom. Some are found to be aggressive and always fighting in the classroom. There are instances whereby pupils with physical disabilities have inflicted serious injuries on their peers in and outside the classroom (for example using their crutches to beat or fall peers down). Omilegbe (2005) stressed further that the epileptic usually frightens his peers in the classroom as a result, disrupts class activities for the day.

v. Lack of Motivation for Teachers and Poor Monitoring of Special Educational Programme: In the research work carried out by Kanu et al (2005) the result showed that motivation of teachers and poor monitoring of the programme affects the development of the programme for special needs of the pupils. Osuorji (2009) affirmed that most coordinators of special education programmes in Lagos state are not special educators and they lack knowledge of interpreting policies of education as it relates to special education, worst still of using the strategies in teaching and training children with special needs. Other hindrances include: lack of accurate and up to date of children with disabilities in Lagos state as well as legislative backing. Due to non-availability of schools for children with disabilities, many parents keep their wards at home especially in the rural areas, those who can afford the fees enroll their children in privately owned centres.

\section{THE NEED FOR IMPLEMENTATION OF POLICY ON CHILDREN WITH PHYSICAL CHALLENGES}

The current worldwide trend with regards to education of physically challenged children is inclusive education. It is an era of equalization of opportunities for all irrespective of race, ethnic or disabilities. The need for implementation of the policy concerning physically challenged children should start from home, the immediate family. As home is the first point of contact for a child, the love, friendly environment and personal relationship a child receives from home will surely show or have effect (positive or negative) on the child in the future. A child with physical disability (amputated hand or epilepsy) needs love. According to Abraham Maslow hierarchy of need, if the physiological needs i.e. safety needs, love and belonging needs, self-esteem needs and self actualization needs of a child are satisfied he or she will become operative in life (Maslow, 1943). In other words, caring, feeding, safety, protection, encouragement in developing potentials of the physically challenged children from the childhood stage will give them a sense of belonging and thus enable them to contribute their own quota to the family and nation at large.

There is need for implementation of the policy on physical disabilities. First, there is the need to eradicate labeling and ineffectively educating most children with physical disabilities. In other words, to eradicate the people's view that "nothing good is in them". Implementing the policy would help remove stigmatization or unnecessary labelling with ridiculous names or impressions.

Secondly, to make provision for the education of all children with physical disability as stated in the Millenium Development Goals number two (2) That is, it is for "achieving universal primary education" by the year 2015 . In other words, all children irrespective of language, culture, race or disabilities will be full beneficiaries of primary education as stated in MDG's goals.

There is also the need to ensure that each pupil with physical disability educational needs and services are determined on an individual basis according to the unique needs of a child. Implementation of the policy creates the avenue for the physically challenged children to learn in the same environment with their non - handicapped counterparts and later improve their academic performance and higher achievement in education.

Moreover, the policy implementation on inclusiveness will create an atmosphere of understanding and tolerance that better prepares pupils of all abilities to function in the world beyond schools. The family and the society which this set of children reside will have opportunity to be involved in planning or placement decisions regarding them and contribute their quota towards these children.

The stated objectives on health programmes, infrastructural planning (roads, hospitals etc), job opportunities, nondiscrimination and so on will give these children advantage to be full beneficiaries of the amenities provided. The integration would help to promote the social development of the physically challenged children as they interact with their non- handicapped peers. It therefore, removes inferiority complex (Jegede, 1999). 


\section{CONCLUSION}

The following conclusions are drawn from the findings of this study. Most stakeholders in the disability programme i.e. teachers, parents and children in the study area have little awareness on the programme. However, it was with a lot of deficiencies in the programme such as:

Non-availability of official cannot be neglected or ignored. It was quite unfortunate that those officials that are meant to monitor the school system are not enough. In the same vein, those few officials that are in the system could not make themselves available for proper monitoring and effectiveness.

Consequently, the ratio of qualified trained teachers is ridiculously low. Most teachers that are teaching these pupils are those that are trained for the normal school system. Whereas, the teachers of the physically challenged children are meant to be trained from and for specialized schools. Thus, the methods or techniques of teaching will be used according to the peculiarity of the pupils. This means that, we have unqualified teachers teaching the pupils in schools.

Basically, there is lack of equipment and resources to teach the physically challenged children. Provision of equipment and teaching aids or instructional materials are not provided. Thus, teaching and learning cannot be said to be taken place in an expected ideal situation. Also, negative attitudes of some learners towards the disabilities in classroom setting in special schools were observed. Many pupils behaved strangely to some pupils that are physically challenged. This negative attitude impedes learning.

Every Nigerian including the disabled has a right to education. This right is stated in the National Policy on Education (Federal Republic of Nigeria, 2014) where it is stated that "equal education opportunities for all children, irrespective of their physical, sensory, mental, psychological or emotional stability in order to fully contribute their own quota to the development of the nation". Most disabled persons were either not admitted to schools or referred to special schools to learn.

Lack of co-operation between parents and agencies concerning the physically challenged children and absence of physically challenged children in the schools in the study area. The society counted the educational needs of the special persons as something not important.

Finally, most head teachers and teachers have not received enough training or attended workshop on proper implementation of programme for physically challenged children. The needs for conferences and in - service training have not been given much attention, especially on inclusive education.

\section{RECOMMENDATIONS}

Based on the findings of the study, the researcher would like to recommend as follows:

- Rigorous advocacy programme should be embarked upon by government to educate all but majorly, every individual who has a stake in the care and education of the physically challenged children on their role in the implementation of government policy concerning the disabled.

- Organization of regular workshops, conferences and seminars for all teachers on strategies for teaching the physically challenged children in their classes should be a major priority of government.

- Incentives should be given to teachers who teach the children with disabilities.

- At the school level, teachers should collaborate with each other to share their experiences. This will help them to provide possible solutions to the problems encountered during the teaching and learning activities with the physically challenged children in classroom.

- Finally, general community should be enlightened on why the physically challenged children are being educated alongside the normal children in a normal classroom setting.

\section{REFERENCES}

- Adamu, S. (2009): New life for the physically challenged. Publish in the Nation newspaper retrieved on 1/3/2010, from http://thenation on uneg.net/web2/articles/24677/1/New-life-for-the-physicallychallenged/page.html

- Ajobiewe, T. (2000): Management of disability in the family. Ibadan Omo-Oje Press

- Anyaele, D. (2012) in National Mirror Newspaper, September, $24^{\text {th }} 2012$.

- Elwan, A (1999): "Poverty \&disability. A survey of the literature "Social protection discussion paper number 9932. World Bank. Washington .D.C.

- Fareo, D.O. (2012): Special Schools and Mainstreaming Programme in Nigeria and lessons for $21^{\text {st }}$ century.

- Federal Republic of Nigeria (2014): National Policy on Education. Lagos: NERDC Press.

- Folabi \& Akanbi (2009): Nigerians celebrate national day for disabilities. Nigerian daily trust newspaper, August $18^{\text {th }}, 2009$. 
- Jegede, A.A (1999) : A case for mainstreaming in educating handicapped children. The Academic review 2 (1), $45-50$.

- Kanu, S.A., Lazarus, K.U. and Ikujini, J.A. (2005): Factors Hindering the Development of Programmes for Children with Learning Disabilities in Lagos State, Nigeria. African Journal of Cross-Cultural psychology and sport facilitation vol. 7. NO. 18-25

- $\quad$ Kirk, S.A. and Gallager, J.J. (1989): Educating exceptional children $6^{\text {th }}$ edition. Houghton Mifflin co. Boston.

- Kotso, J.A. (2010): Information Resources and Services to Physically Challenged in Plateau State Special Education Institutions Samaru Journal of Information Studies vol. 10. No. 1 \& 2

- $\quad$ Lang. R. and Upah, L. (2008): Scoping study: Disability issues in Nigeria, final report. London Leonard Cheshire Disability and inclusive development centre, University College, London.

- Longman Dictionary of Contemporary English $5^{\text {th }}$ ed. (LDOCE5): 2005 .Education for advanced learners. Longman corpus network, British.

- Inclusion International (2006): Hear our voices: a global report; people with an intellectual disability and their families speak out on poverty and exclusion. United Kingdom

- Maslow, A.H. (1943). A theory of Human Motivation. Psychological Review. 50(4), 370-96. Retrieved from http://psychclassics.yorku.ca/Maslow/motivation.html

- Obazni, T.C. (2006): Teaching pupils with special education needs in the regular classroom. Book Builders Editions, Africa, Ibadan.

- $\quad$ Oladejo, M.A. (2011) Educating Students with disabilities in Nigeria: some challenges and

- Policy Implications. European Journal of Humanities and Social Sciences, vol.3 no.1

- Omiegbe,O.(2005): Managing Special Needs Children in the Regular classroom. Special Educator Vol. 7, No 1, September p. 27-33.

- Osuorji, P.I. (2009): Problems of inclusion in educating students with disabilities. Being article contribution for Journal of Education, Faculty of Education, University of Burea Cameroun (Unpublished work).

- $\quad$ Silverstone, R. (2000): The Emerging Disability Policy Framework: A Guide Law Review 85(5).

- Smith, D.D. (2007): Introduction to special education making a difference. Library of congress

- cataloguing-in-publication data.

- Utley, C.A. \& Obiakor, F (eds) (2004): Special education, multicultural education and school reform components of quality education for learners with mild disabilities. Springfield, I.L. Charles, C. Thomas Publishers.

- Uyanwa, C.N. and Akanbi, B.D. (2002): Educational Programmes for Special Needs Children in Nigeria Journal of Emotional Psychology and Sports Ethics. 4. 44-49.

- UNICEF (2009): The United Nations Children's Fund: The State of the World Children. Maternal and newborn health.

- United Nations Children's Fund (UNICEF) (2003): Office of the United Nations High Commissioner for Human Rights, "Convention on the rights of the child". The policy press.

- World Health Organisation (1980): International classification of impairments, disabilities and handicaps. Resolution World Health Organisation 29 : 35 of the twenth ninth world health assembly in Geneva. 